Original Research Article

\title{
Assessment of levetiracetam and valproic acid as monotherapy for quality of life in partial epilepsy patients
}

\author{
Sanjay Kumar Verma ${ }^{1}$, Suman Bala ${ }^{2}$, Yashpal Singh ${ }^{2}$
}

${ }^{1}$ Department of Pharmacology, Muzaffarnagar Medical College, Muzaffarnagar, Uttar Pradesh, India

${ }^{2}$ Department of Pharmacology, Himalayan Institute of Medical Sciences, Dehradun, Uttarakhand, India

Received: 08 September 2019 Revised: 13 September 2019 Accepted: 27 September 2019

*Correspondence to: Dr. Sanjay Kumar Verma, Email: skverma10101@ gmail.com

Copyright: (C) the author(s), publisher and licensee Medip Academy. This is an openaccess article distributed under the terms of the Creative Commons Attribution NonCommercial License, which permits unrestricted noncommercial use, distribution, and reproduction in any medium, provided the original work is properly cited.

\begin{abstract}
Background: Quality of life (QOL) is important in patients of epilepsy as it is affected both by disease as well as therapy. QOL is the most overlooked component of antiepileptic treatment.

Methods: An observational analytical study was conducted in the Department of Pharmacology in collaboration with Department of Neurology of Himalayan Institute of Medical Science, Dehradun over 12 months. 80 patients satisfying inclusion criteria were enrolled and divided into two groups based on physician discretion and followed up for 12 weeks. Patients were evaluated at 0 and 12 weeks for quality of life using QOLIE-10 self-administered questionnaire, they were also assessed for seizure control and drug related adverse effects.

Results: 60 patients were enrolled and divided into two treatment groups as per physician discretion, levetiracetam (30) and valproic acid (30) groups. Study groups showed significant improvement in QOL (mean change in QOL17.95 \pm 2.527 for LEV and 11.56 \pm 3.540 for VPA). Levetiracetam (LEV) group showed significant improvement over valproic acid (VPA) group $(\mathrm{p}=0.05)$ at 12 weeks. Patients who achieved total seizure control at 6 weeks were $93.33 \%$ patients in levetiracetam and $90 \%$ in valproic acid group, reason being non adherence which was $6.67 \%$ and $10 \%$ respectively. Adverse event recorded with levetiracetam (03), most common being drowsiness and with valproic acid (08), with most common being anorexia.

Conclusions: Levetiracetam therapy has led to better quality of life and has the same seizure control as valproic acid, and has shown to have lower incidence of adverse effect.
\end{abstract}

Keywords: Partial epilepsy, Quality of life, QOLIE-10, Levetiracetam, Valproic acid

\section{INTRODUCTION}

Epilepsy is a common neurological disorder manifesting as recurrent neuronal discharges which may be limited to either one region (focal or partial) or diffusely spread over multiple regions (generalized tonic clonic seizure (GTCS)) of brain and is characterized by loss of consciousness which is preceded by cry, foaming, twitching and vigorous jerky movements of limbs. The annual incidence of epilepsy in world population is $50 / 100000$ and that in the Indian population is 27.3 per 100000 with prevalence of 5.59 per $1000 .^{1,2}$
For the most definitely diagnosed epilepsy, long-term treatment with anti-epileptic drugs (AEDs) is needed. ${ }^{3}$ Monotherapy is considered the gold standard in epilepsy and is preferred over polytherapy because of lesser risk of adverse events and drug interactions, the decreased cost of therapy and greater patient compliance. ${ }^{4}$

Adverse effects (diplopia, ataxia, sedation, cognitive issues, hyponatremia, headache, weight gain, dizziness, depression and paresthesia) occur at therapeutic doses in patients of epilepsy. Adverse effects of drugs also play a major role in ensuring quality of life in epilepsy patients along with the effects of epilepsy. 
There are many disease specific tools for measurement of quality of life. These tools are in the form of questionnaire that can be administered to patients in the outpatient department. These tools help assess effect of both disease as well as treatment administered. Epilepsy specific tools are (Research and Development Corporation (RAND) 36- Item Health Survey (SF-36), Quality of life in Epilepsy (QOLIE-89, QOLIE-31 and QOLIE-10).

Efficacy of conventional AEDs has been well established but the area they lack is in the adverse effect caused by them. Newer AEDs though were started as add-on therapy to the conventional AEDs and have shown equal efficacy to conventional AEDs. Newer AEDs with their better safety profile hold an edge over the conventional AEDs. In this study we conceptualized comparing broadspectrum AED from the older generation which is VPA with a drug of newer generation i.e. LEV. LEV has found its usage both approved as well as off label use in majority of types of seizures. Even after extensive search there was a lack of studies which compared VPA with LEV on efficacy, safety and quality of life both in India as well as world till date.

Hence this study was planned to compare valproic acid and levetiracetam as monotherapy for comparison of quality of life in patients of partial seizures.

\section{METHODS}

This was an observational analytical follow-up study in newly diagnosed patients of partial seizure. Study was conducted over a period of one year from January 2016 to December 2016. Minimum sample size which was required was 60 patients, with 30 patients in each group. Sample size was based on previous study which compared quality of life in epilepsy patients. ${ }^{5}$ Ethical clearance was taken from Institutional Ethical Committee. Patients were included after taking a written informed consent. Patients were selected from out-patient department of Department of Neurology. Patients were followed up for a period of 12 weeks. Patient satisfying below mentioned inclusion criteria were included in the study: Patients with diagnosis of partial epilepsy, both sexes in the age group of 18-60 years, patients who have been stabilized on their respective drug dosage for more than 1.5 months or less than 4.5 months. Subjects excluded from the study were patients suffering from any other type of epilepsy, patients with progressive CNS disease and lesion, any uncontrolled co-morbid condition, malignancy, hypersensitivity to the study drugs, participating in another study, subjects with deranged liver and renal functions, pregnant and lactating mothers, patients who have experienced acute onset of seizures related to drugs, alcohol, acute medical illness, patients leaving the study due to any reasons will be excluded from final analysis. Demographic profile and detailed history was obtained from each recruited patients; this included family history, educational status, age of onset of epilepsy, duration of disease, personal habits. A general physical examination was performed and blood pressure was recorded EEG and CT heads was done. Blood test (haematological and biochemistry were done before starting of the treatment. Study subjects included in the study were divided into two groups of 30 each. The drugs were given to subjects on the basis of physician's discretion. The dose ranges of the two drugs at the start of the study were as follows for levetiracetam (LEV) 500$2000 \mathrm{mg} /$ day and for valproic acid (VPA) 300-1000 mg/ day. After recruitment patients were assessed for the qualities of life based on QOLIE-10 questionnaire, and were also evaluated for efficacy and safety. Patients were evaluated at 0,6 and 12 weeks or earlier as the need arose. For efficacy and safety they were assessed on each visit with the help of patient maintained seizure diary, and self-reporting of adverse drug reaction. Patients were evaluated at baseline ( 0 visit) and at 12 weeks for quality of life.

Assessment of quality of life in patients: The QOLIE-10 is a brief standardized instrument for screening patients with epilepsy about the impact of epilepsy on their lives. QOLIE-10 evaluates patients in three domains: (i) epilepsy effects which evaluated patients for memory, physical effects and mental effects, (ii) mental health assessing for energy, depression and overall quality of life, (iii) role functioning which evaluated patients for seizure worry, work, driving and social limits. Scores for QOLIE- range from 1-5 for each question with minimum of 10 and maximum of 50. Higher the score poor is the expressed quality of life. Assessment of safety of treatment: A checklist of adverse drug reaction was prepared according to the most common adverse events occurring due to study drugs. Adverse drug reactions were recorded at every visit of the patient i.e. at monthly intervals. Seizure diary was used to record patient's experiences weekly and how their seizures improved or deteriorated, frequency of seizures, duration, post-ictal confusion seizure related injury.

Data management and analysis was done using Microsoft Excel 2007 and IBM SPSS version 20.0. Demographic data was presented as either frequency or mean \pm SD. Intra-group comparison was done using paired sample student t-test and inter-group analysis was done using unpaired student t-test. Adverse events were interpreted and analyzed using descriptive statistics and chi-square test.

\section{RESULTS}

Total 80 patients were included after primary screening. Out of these 13 patients were less than 18 years, 7 were above 60 years of age, hence total no. of patients included for final analysis were 60 out of which 30 were in the LEV group and 30 in the VPA group.

Basic demographic profile of the patients included in the study is given in Table 1. 
Table 1: Basic demographic detail of the study group.

\begin{tabular}{|c|c|c|c|}
\hline \multicolumn{2}{|c|}{ Characteristic } & $\operatorname{LEV}(\%)$ & VPA (\%) \\
\hline \multicolumn{2}{|c|}{ Age $($ years $) *($ Mean \pm SD $)$} & $\begin{array}{l}28.05 \pm \\
11.853\end{array}$ & $\begin{array}{l}23.00 \pm \\
5.279\end{array}$ \\
\hline \multirow{2}{*}{ Sex } & Male & $19(63.33)$ & $12(40)$ \\
\hline & Female & $11(36.66)$ & $18(60)$ \\
\hline \multirow{2}{*}{ Religion } & Hindu & $25(83.33)$ & $26(86.66)$ \\
\hline & Muslim & $5(16.66)$ & $4(13.33)$ \\
\hline \multirow{2}{*}{$\begin{array}{l}\text { Marital } \\
\text { status }\end{array}$} & Married & $14(46.66)$ & $8(26.66)$ \\
\hline & Unmarried & $16(53.33)$ & $22(73.33)$ \\
\hline \multirow{2}{*}{ Education } & $\begin{array}{l}\text { Below } \\
\text { Intermediate }\end{array}$ & $17(56.66)$ & $15(50)$ \\
\hline & Intermediate & $13(43.33)$ & $15(50)$ \\
\hline \multirow{2}{*}{ Residence } & Urban & $19(63.33)$ & $11(36.66)$ \\
\hline & Rural & $11(36.66)$ & $19(63.33)$ \\
\hline \multirow{2}{*}{ Smoking } & Smoker & $10(33.33)$ & $9(30)$ \\
\hline & Non-smoker & $20(66.66)$ & $21(70)$ \\
\hline \multirow{2}{*}{ Alcohol } & Alcoholic & $10(33.33)$ & $10(33.33)$ \\
\hline & Non-alcoholic & $20(66.66)$ & $20(66.66)$ \\
\hline \multirow{2}{*}{ Diet } & Vegetarian & $16(53.33)$ & $15(50)$ \\
\hline & Non vegetarian & $14(46.66)$ & $15(50)$ \\
\hline
\end{tabular}

There was no significant difference between the two groups based on the baseline characteristics.

Baseline pattern in included patients for epilepsy which are included in this are family history, duration of disease and frequency of seizures (Table 2).

Table 2: Baseline pattern of epilepsy among both the study groups.

\begin{tabular}{|llll|}
\hline \multicolumn{2}{|l|}{ Parameters } & LEV (30) & VPA (30) \\
\hline $\begin{array}{l}\text { Family } \\
\text { history }\end{array}$ & Present (\%) & $5(16.66)$ & $6(20)$ \\
\hline Age of onset (years) & $25(83.33)$ & $24(80)$ \\
\hline Duration (years) & $4.37 \pm 2.587$ & $4.12 \pm 1.821$ \\
\hline $\begin{array}{l}\text { Seizure frequency } \\
\text { (episodes/month) }\end{array}$ & $3.37 \pm 0.831$ & $3.19 \pm 0.834$ \\
\hline \multirow{2}{*}{\begin{tabular}{l} 
*p $<0.05$ was considered significant, student t-test. \\
\hline
\end{tabular}}
\end{tabular}

Quality of life in these patients was recorded both at start of study and at the end of 12 weeks. Quality of life was assessed using QOLIE-10 questionnaire. The comparison was done both within the groups as well as between the groups (Table 3-5).

Study subjects included were also assessed for voluntary reported adverse effects which are given in (Table 6).

Adherence was assessed at 6 and 12 weeks. $6.67 \%$ and $10 \%$ in LEV and VPA group were found to be non adherent and these also suffered from seizure episode during the study period. Cost comparison was also done to see the total cost of monthly therapy which was INR $1394 \pm 209.427$ for LEV and 706.25 \pm 152.616 for VPA.
Table 3: Comparison of mean QOLIE-10 scores in LEV group.

\begin{tabular}{|c|c|c|c|}
\hline $\begin{array}{l}\text { QOLIE-10 } \\
\text { parameters }\end{array}$ & Baseline & 12 weeks & $\begin{array}{l}P \\
\text { value }\end{array}$ \\
\hline Epilepsy effects & $10.05 \pm 0.911$ & $5.21 \pm 0.918^{*}$ & \multirow{4}{*}{0.000} \\
\hline Mental effects & $9.95 \pm 1.715$ & $4.63 \pm 1.116^{*}$ & \\
\hline Role function & $14.58 \pm 1.465$ & $6.79 \pm 1.084^{*}$ & \\
\hline Total & $34.58 \pm 1.835$ & $16.63 \pm 1.832^{*}$ & \\
\hline
\end{tabular}

Table 4: Comparison of mean QOLIE-10 scores VPA group.

\begin{tabular}{|c|c|c|c|}
\hline $\begin{array}{l}\text { QOLIE-10 } \\
\text { parameters }\end{array}$ & Baseline & 12 weeks & $\begin{array}{l}P \\
\text { value }\end{array}$ \\
\hline Epilepsy effects & $8.63 \pm 1.360$ & $5.06 \pm 1.389^{*}$ & \multirow{4}{*}{0.000} \\
\hline Mental effects & $8.81 \pm 1.559$ & $5.31 \pm 1.195^{*}$ & \\
\hline Role function & $11.56 \pm 1.711$ & $7.06 \pm 1.237^{*}$ & \\
\hline Total & $29.00 \pm 3.204$ & $17.44 \pm 1.413^{*}$ & \\
\hline
\end{tabular}

$* \mathrm{p}<0.05$ was considered significant, student t-test.

Table 5: Comparison of the difference of mean change in QOLIE-10 score based on types of seizure at 12 weeks between the groups.

\begin{tabular}{|c|c|c|c|}
\hline $\begin{array}{l}\text { QOLIE-10 } \\
\text { parameters }\end{array}$ & $\begin{array}{l}\text { Group A } \\
\text { (LEV) }\end{array}$ & $\begin{array}{l}\text { Group B } \\
\text { (VPA) }\end{array}$ & $\begin{array}{l}P \\
\text { value }\end{array}$ \\
\hline Epilepsy effects & $4.84 \pm 1.463$ & $3.56 \pm 1.750^{*}$ & \multirow{4}{*}{0.000} \\
\hline Mental effects & $5.32 \pm 1.945$ & $3.50 \pm 1.966^{*}$ & \\
\hline Role function & $7.79 \pm 1.988$ & $4.50 \pm 2.191^{*}$ & \\
\hline Total & $17.95 \pm 2.527$ & $11.56 \pm 3.540^{*}$ & \\
\hline
\end{tabular}

Table 6: Adverse events recorded during the course of study.

\begin{tabular}{|lll|}
\hline Adverse events & $\begin{array}{l}\text { LEV } \\
(\mathbf{n}=\mathbf{3})\end{array}$ & $\begin{array}{l}\text { VPA } \\
(\mathbf{n}=\mathbf{8}) *\end{array}$ \\
\hline Irritability & 1 & 1 \\
\hline Anorexia & 0 & 4 \\
\hline Drowsiness & 2 & 2 \\
\hline Loose motion & 0 & 1 \\
\hline
\end{tabular}

*Chi-square test, Chi-value 2.783, $\mathrm{p}=0.0953$.

\section{DISCUSSION}

The ultimate goal for treatment of epilepsy is providing patients with a life free from seizures in combination with optimal quality of life. Inclusion of evaluating quality of life outcomes in the standard management plan along with traditional measures of assessment of seizure frequency and adverse effects needs to be encouraged. To address this objective, the present study compares the drugs levetiracetam and valproic acid on the basis of the quality of life in newly diagnosed patients with epilepsy.

Demographic details included in this studies were age, gender, and place of residence. Mean age of population in 
this study was $28.05 \pm 11.853$ years and $23.00 \pm 5.279$ years in LEV and VPA groups respectively which was similar to a study where mean age of the patient was $31.8 \pm 11.0$ years. ${ }^{7}$ In present study male to female ratio in whole study population was 52:48 which was different from the same study where it was 57:44 but not a very marked difference. ${ }^{7}$ Rural urban divide among the patients included in the study groups was also seen which was 63.33 and 36.66 in LEV group and 36.66 and 63.33 in VPA group (Table 1).

The mean duration of illness in LEV group was $4.37 \pm 2.587$ years and in VPA it was $4.12 \pm 1.821$ years (Table 2) which was lower than another study where the mean duration of the disease was found to be $6.62 \pm 4.21$ years. $^{8}$ There were no episodes of status epilepticus recorded in both groups during the entire duration of this study as all patients at the time of enrollment had already completed the titration phase. People with positive family history were found in both groups and were $16.66 \%$ and $20 \%$ in LEV and VPA group respectively (Table 2). This result was a higher as compared to another study. ${ }^{8}$

Epilepsy is a medical and social diagnosis as epileptic individuals face numerous psycho-social problems (anxiety, social stigma, driving troubles, unemployment), which can negatively influence the quality of their lives. The growing awareness of the importance of the psychosocial effects of epilepsy has led to the need to measure the quality of life of affected individuals. Therefore, the proper use of AEDs as well as the monitoring of adverse impacts as a result measure, and the assessment of quality of life are important for the management of epilepsy in addition to the optimal seizure control. ${ }^{9}$ Standardized QOLIE-10 questionnaires were the main measurements of the quality of life assessed for our research. The QOLIE10 questionnaire evaluates three elements of the epileptic patient's health: epilepsy effects, mental impact and role functions. The score for each scale was calculated, together with the QOLIE-10 complete score. $^{10}$

In the beginning of the trial, baseline QOLIE-10 score was $34.58 \pm 1.835$ for LEV group, which at the end of 12 weeks decreased to $16.63 \pm 1.832$ (Table 3 ), which showed a significant mean change of $17.95 \pm 2.527$ (Table 5). Score values showed a $35.9 \%$ increase over the baseline in the LEV group. This was backed by a research carried out by SS Hassan et al. that showed a percentage change of $34.82 \% .^{11}$ In this research the subgroup analysis also showed improvements in all areas where distinct aspects of the results QOLIE-10 were compared. The mean change in effects of the epilepsy $(4.84 \pm 1.463)$, mental $(5.32 \pm 1.945)$ and role functions $(7.79 \pm 1.988)$ (Table 5). The role function in the current study showed the greatest improvement.

The baseline score in the initial study QOLIE-10 VPA group was $29.00 \pm 3.204$ which at the ends of 12 weeks was reduced to $17.44 \pm 1.413$ (Table 4), showing a mean change $11.56 \pm 3.540$ which was statistically significant $(\mathrm{p}<0.05)$ (Table 5). In the VPA group, the results showed an improvement of $23.12 \%$. Two different studies have supported these findings. SANAD trial comparing VPA to LTG and TPM. ${ }^{12}$ Similar research was conducted in Spain comparing VPA and LTG which showed improvements in the quality of life from baseline. ${ }^{5}$ Subgroup analysis showed improvement in all spheres. The mean change in epilepsy effect $(3.56 \pm 1.750)$, mental effects (3.50 \pm 1.966$)$ and role function effects $(4.50 \pm 2.191)$ (Table 5). Role function showed the maximum improvement.

We could not find studies where these two drugs were compared head to head even after an extensive literature search. Inter group comparison between the two groups showed statistically significant $(\mathrm{p}<0.05)$ difference in mean change in QOLIE-10 score i.e. 17.95 \pm 2.527 for LEV and 11.56 \pm 3.540 (Table 5).

Seizure freedom is an important parameter for measuring the effectiveness of epileptic treatment. The duration of treatment is determined by how quickly seizure control is accomplished as well as how well seizure control is done. This was therefore evaluated by the seizure diary reported in our research by patients. The monthly mean seizure frequency in LEV and VPA at the start of the trial was $3.37 \pm 0.831$ and $3.19 \pm 0.834$ (Table 2). The seizure rate was lower than in other epilepsy studies, but this could result from newer patients who have participated in this study. ${ }^{13}$ The total seizure freedom of patients at 6 weeks was $93.33 \%, 90 \%$ was LEV and VPA, and at 12 weeks $100 \%$ patients were seizure free. This is consistent with another study where seizure freedom between older and new AEDs did not differ. ${ }^{14}$

Medicament adherence is significant in the treatment of chronic diseases such as epilepsy; it can influence the recurrence of the seizure and impact the quality of life. Adherence in our research was evaluated by counting pills. The adherence of LEV and VPA groups (not statistically significant $\mathrm{p}<0.05$ ) was $93.33 \%$ and $90 \%$ at 6 weeks, which could be caused by more adverse effects as compared to LEV as a result of the VPA. Enhanced compliance improves quality of life. ${ }^{15}$ Adverse drug reaction is an important factor that can demotivate patients to continue the treatment. Adverse effect leads to reduced adherence to medication resulting in enhanced likelihood of seizure episodes resulting in lower quality of life. The adverse events recorded in the present study were based on the adverse effect check list during the entire study period. Total number of adverse events reported in the research was 11 , out of which 8 reported with VPA and 3 with LEV (Table 6). It were found that both groups did not differ significantly. As we did not find any head to head comparison of our study drugs we tried to correlate results with other studies which compared older versus newer AEDs. Our findings were in accordance with other studies where it was inferred that 
both do not differ statistically in terms of adverse events. ${ }^{16}$ Adverse event in group LEV group were drowsiness (2) and irritability (1). In VPA adverse events were anorexia (4), drowsiness (2), irritability (1) and loose stools (1). The most common adverse effect in LEV group was drowsiness and in VPA group were anorexia (Table 6).

An important part of any study which compares two different drugs is to assess for the cost-benefit ratio in terms of efficacy and safety. In the present study, we determined that the average monthly cost of therapy for LEV was INR $1394 \pm 209.427$ and for VPA was INR 706.25 \pm 152.616 . There was a significant difference in monthly cost of the two drugs, but this did not affect the patient's adherence as is expected with costly medication. As cost is an important factor which determines the continuation of medication by patients as stated by another study. ${ }^{17}$

Anti-epileptic treatment effectively controls seizure in patients of epilepsy. Both the drugs in our study effectively provided seizure control. Both the drugs in the study provide a positive influence on quality of life. Quality of life was not affected by gender. Seizure type and treatment administered has a positive influence on quality of life. There were no serious adverse events in this study in both groups.

The major limitation of our study was its short duration and only monotherapy was included. The results of the present study does not give information about the epilepsy pattern and its effect in patients less than 18 years and more than 60 years as well as in pregnant females or patients with co-morbid conditions. In spite of this it can pave path for further studies which can compare newer AEDs with older AEDs for comparison of quality of life in epileptic patients which is mostly overlooked.

Antiepileptic drugs are the mainstay of epilepsy treatment. In the present study it was seen that LEV as compared to VPA was equal in efficacy in terms of seizure control, lesser side effects and showed significant improvement in terms of quality of life in patients of GTCS.

\section{ACKNOWLEDGEMENTS}

Authors would like to thank Himalayan Institute of Medical Sciences, Dehradun to have provided me the opportunity to conduct my research work. I acknowledge the contribution of my colleagues in the department and also indebted to all patients who consented to participate in this study.

\section{Funding: No funding sources} Conflict of interest: None declared

Ethical approval: The study was approved by the Institutional Ethics Committee, approval number SRHU/HIMS/ETHICS/2017/111

\section{REFERENCES}

1. Tatum WO IV, Benbadis S, Vale FL. The neurosurgical treatment of epilepsy. Arch Fam Med. 2000;9:1142-6.

2. Banerjee TK, Ray BK, Das SK, Hazra A, Ghosal MK, Chaudhuri A, et al. A longitudinal study of epilepsy in Kolkata, India. Epilepsia. 2010;51:238491.

3. Nelson LP, Savelli-Castillo I. New antiepileptic agents. Pediatr Dent. 2004;26:58-62.

4. Kaminow L, Schimschock JR, Hammer AE, Vuong A. Lamotrigine monotherapy compared with carbamazepine, phenytoin, or valproate monotherapy in patients with epilepsy. Epilepsy Behav. 2003;4:659-66.

5. Viteri C, Codina M, Cobaleda S, Lahuerta J, Barriga J, Morales MD. Quality of life in Spanish epilepsy patients on monotherapy with Lamotrigine or Valproic acid. Seizure. 2010;19:432-8.

6. Cramer JA, Perrine K, Devinsky O, Meador K. A brief questionnaire to screen for quality of life in epilepsy: the QOLIE-10. Epilepsia. 1996;37(6):57782.

7. Norsa'adah B, Zainab J, Knight A. The quality of life of people with epilepsy at a tertiary referral centre in Malaysia. Health and Quality of life Outcomes. 2013;11:143-8.

8. Shanmukhi S, Sita Jayalakshmi S, Anand B. Factors associated with quality of life in adult epilepsy patients-a hospital based study from south India. Res Neurol Int. 2015;1-5.

9. Jacoby A. Epilepsy and the quality of everyday life: findings from a study of people with well-controlled epilepsy. Soc Sci Med. 1992;34:657-66.

10. Cramer JA, Perrine K, Devinsky O, Meador K. A brief questionnaire to screen for quality of life in epilepsy: the QOLIE-10. Epilepsia. 1996;37(6):57782.

11. Suresh S, Chakraborty A, Virupakshaiah A, Kumar N. Efficacy and safety of levetiracetam and carbamazepine as monotherapy in partial seizures. Epilepsy Res Treat. 2015;2015:415082.

12. Marson A, Al-Kharusi A, Alwaidh M, Appleton R, Baker G, Chadwick D, et al. The SANAD study of effectiveness of valproate, lamotrigine, or topiramate for generalised and unclassifiable epilepsy: an unblinded randomised controlled trial. Lancet. 2007;369(9566):1016-26.

13. Tatum WO IV, Benbadis S, Vale FL. The neurosurgical treatment of epilepsy. Arch Fam Med. 2000;9:1142-6.

14. Schmidt D. Efficacy of new antiepileptic drugs. Epilepsy Curr. 2011;11:9-11.

15. Ahmad N, Othaman NI, Islahudin F. Medication adherence and quality of life in epilepsy patients. Int J Pharm Pharm Sci. 2013;5(2):401-4.

16. Roopa BS, Narayan SS, Sharma G, Rodrigues RJ, Kulkarni C. Pattern of adverse drug reactions to antiepileptic drugs: a cross-sectional one-year survey at a 
tertiary care hospital. Pharmacoepidemiol Drug Safety. 2008;17(8):807-12.

17. Das K, Bannerjee M, Mondal GP, Devi LG, Singh $\mathrm{OP}$, Mukherjee BB. Evaluation of socio-economic factors causing discontinuation of epilepsy treatment resulting in seizure recurrence: a study in urban

Cite this article as: Verma SK, Bala S, Singh Y. Assessment of levetiracetam and valproic acid as monotherapy for quality of life in partial epilepsy patients. Int J Basic Clin Pharmacol 2019;8:2434-9. 